\title{
(息)
}

Citation:

Langley, K (2019) You are about to jump out of a plane... Law Teacher, 53 (4). pp. 524-535. ISSN 0306-9400 DOI: https://doi.org/10.1080/03069400.2019.1667093

Link to Leeds Beckett Repository record:

https://eprints.leedsbeckett.ac.uk/id/eprint/6199/

Document Version:

Article (Accepted Version)

This is an Accepted Manuscript of an article published by Taylor \& Francis in The Law Teacher on 30

Sep 2019, available online: http://www.tandfonline.com/10.1080/03069400.2019.1667093

The aim of the Leeds Beckett Repository is to provide open access to our research, as required by funder policies and permitted by publishers and copyright law.

The Leeds Beckett repository holds a wide range of publications, each of which has been checked for copyright and the relevant embargo period has been applied by the Research Services team.

We operate on a standard take-down policy. If you are the author or publisher of an output and you would like it removed from the repository, please contact us and we will investigate on a case-by-case basis.

Each thesis in the repository has been cleared where necessary by the author for third party copyright. If you would like a thesis to be removed from the repository or believe there is an issue with copyright, please contact us on openaccess@leedsbeckett.ac.uk and we will investigate on a case-by-case basis. 
Katherine Langley

Leeds Beckett University

E: k.langley@leedsbeckett.ac.uk

Tw: @KatlLangley

\section{You are about to jump out of a plane...}

\section{$\underline{\text { Abstract }}$}

You are about the jump out of a plane, you can feel your heart pounding in your chest, you take deep breaths to try and calm yourself. The anxiety you are experiencing is palpable. The wind is whipping past your hair; you are grateful for the goggles you were given on the ground. You feel the shiny lycra of the suit you are wearing, and have a clear awareness of the unfamiliar feeling of the parachute harness strapped to you. Your hands unconsciously tug the cold metal rings of the harness: it will be fine, won't it? Think about the smell of the jet fuel, the whirring sound of the engine, of nervous chatter, or the roar of wind rushing past the open plane door. As you clench your palms slightly you feel...

This article examines the effectiveness of an interactive reflection teaching resource used within a clinical legal education pilot study.

\section{$\underline{\text { Introduction }}$}

This paper aims to examine, discuss and critically evaluate the importance of reflection as a creative resource available within the Higher Education setting, particularly within clinical legal education. Further, the paper aims to look at specifically at the technique of interactive reflection within legal teaching as a creative teaching strategy, something that it is often difficult to include within such a large, classical subject. The teaching resource used within the pilot study was interactive reflection; Patten and Inlow $^{1}$ comment that this technique can foster

\footnotetext{
${ }^{1}$ A Patten McGuire, and L Inlow, "Interactive reflection as a creative teaching strategy." Conflict Resolution Quarterly. (2005) 22(3) pp. 365-379.
} 
Katherine Langley

Leeds Beckett University

E: k.langley@leedsbeckett.ac.uk

Tw: @KatlLangley

an increased awareness of evaluation skills, critical thinking and conflict resolution, and serves as a foundation for role-play and other analytical learning activities. The resource was used during a lesson taught to undergraduate Law LLB students at Level 6, the students are all enrolled in the Law Clinic module at Teesside University, a pro-bono service where under supervision the students provide advice on legal issues to members of the public. The subject of the resource was a lesson concerning Judicial Reasoning; the theory being that by applying the reflective tool to a non-legal topic, the students are better able to reason and reflect upon relevant topics within their subject area, namely law. This resource was chosen due to the clear research based benefits of critical reflection of assumptions (CRA), Mezirow ${ }^{2}$ avers that by including critical incidents in learning, the students' learning is enhanced by accessing experiences that promote personal growth; this he referred to as transformative learning. Mezirow's approach is particularly pertinent for clinical education as the intention is for students to grow as people, and as lawyers, and in doing so be able to fully consider the evidence and merits of each case they come across. Transformative learning is also useful in problem solving skills, improving group dynamics and conversely, improving autonomous working skills due to the internal reflection required. Brookfield ${ }^{3}$ as cited below also wrote about using critical incidents to challenge the innate assumptions of learners. Currently, there are an infinite amount of resources to be used in creative teaching including games, pair activities, peer or group work, physical presentations, and videos, with each resource having a differing degree of success dependent on the topic, students and level taught. Law Schools

\footnotetext{
2 J Mezirow, “On critical reflection.” Adult Education Quarterly. (1998) 48(3) p185.

${ }^{3}$ S Brookfield, Becoming a Critically Reflective Teacher, (Jossey Bass, 1995)
} 
Katherine Langley

Leeds Beckett University

E: k.langley@leedsbeckett.ac.uk

Tw: @KatlLangley

across the world place a heavy emphasis on "thinking like a lawyer", or legal reasoning, though it is difficult to problem solve a legal issue without having all of the foundation knowledge of the law to work through. Some academic studies are proposing, and trialling an overhaul of the traditional legal curriculum in favour of a curriculum based around critically thinking and problem solving transcending a more traditional modular approach.

\section{Structure of the Pilot Study Resource}

Within the pilot study, the interactive reflection resource concerned skydiving; video footage was used to show a person inside an aeroplane preparing to jump. Reflection was conducted in three sections and the video paused at intervals. Initially, the reflection was internal and personal to the students, who were asked to close their eyes and consider the smells, feel of the suit, and sound of the wind past the door, feelings of nervousness, anxiety, and excitement. This personal narrative aspect of the exercise was designed to get the students working within the scenario, and this endorses the theories as set out by Mezirow ${ }^{4}$. Within a legal education setting, developing a student's ability to critically reflect also drives student motivation and engagement within their learning activities, as students are in essence, formatively assessing their own work regularly, an important tool for life in any legal practice. Critical reflection itself, for all its learning benefits and wide application, it for students is an inherently difficult skill to master; in this regard, incorporating this into more of the legal curriculum, is also a challenge. Many law schools in recent years have turned to clinical legal education to adapt to an evolving and varied life in practice, and prepare students for this. This more practical application of student's skills is innovative, and vastly different to the rote learning which students are so accustomed to when they have progressed to HE settings.

\footnotetext{
${ }^{4}$ J Mezirow (n.2)
} 
Katherine Langley

Leeds Beckett University

E: k.langley@leedsbeckett.ac.uk

Tw: @KatlLangley

Next, the students are asked in pairs to consider the subsequent aspects of the video, looking at the person moving towards the edge of the aeroplane door. The pairs are asked to consider the consequences of a person continuing to jump, and a person choosing to abort the jump. This is reflective of the work judges do in considering the aggravating and mitigating factors of any decision, and the pair work brings another persons' perspective into the initial stages of evaluation. Surface and procedural approaches to legal reasoning ignore these elements of critical thinking that infuse the law, such that critical thinking may rarely be taught Converse to legal reasoning, is critical thinking, to law students explicitly, and usually left for students to work out for themselves, sometimes, after their studies are completed. By working to incorporate critical thinking, and reflection into more of the legal curriculum, students will be able to interpret, analyse and evaluate problems more effectively, including their own performance. Weinstein and Morton ${ }^{5}$ call upon law teachers to do a better job of incorporating and supporting creative thinking, and reflection in legal education. It is possible that the rise of clinical legal education would provide the correct vehicle to promote this. Of course, law clinics are limited in the scope of the cases that they take, and the areas of law covered, the amount of students able to participate, and many other factors which mean that for the time being, clinical legal education is varied across England and Wales, and other jurisdictions.

The final section of the video shows the person jumping from the aeroplane, and skydiving before the parachute is opened. In different pairs, the students are asked to consider the effect on the skydiver of the external, and perhaps immovable factors such as location, weather, and timing, safety record of the company, gravity, and potential experience of the jumper. This

\footnotetext{
${ }^{5} \mathrm{~J}$ Weinstein and L Morton, "Stuck in a rut: the role of creative thinking in problem solving and legal education" Clinical Law Review, (2003) vol 9, p835.
} 
Katherine Langley

Leeds Beckett University

E: k.langley@leedsbeckett.ac.uk

Tw: @KatlLangley

section of the exercise mirrors the fact that the law is sometimes the immovable element to a judges' decision-making, and whilst the judge may have a personal view on the topic, this is not always commensurate with the decision made due to external factors, something that should always be measured by the law students.

The final aspect of the task is to share what the pairs' thoughts were about the aggravating and mitigating aspects of skydiving, and explore as a larger group how this was altered by the external and immovable factors. The second activity is linked to the reasoning task and is of the lesson was to look at a case of their own, currently ongoing, determining whether there are any factors which should have greater consideration, applying their developed reasoning skills the facts of a real case.

\section{Pilot Study Resource}

The model of the resource used in the pilot study of reflection in clinical legal education was based around Mezirow's Critical Incident Theory ${ }^{6}$, however, for the purposes of reflection on the effectiveness of the resource as designed, Brookfield's Four Lenses Model ${ }^{7}$ will be used. Brookfield's model asks the person reflecting to look at the situation via four 'lenses', first the autobiographical lens or what one personally thinks after the delivery of the session or event. Secondly, the view of the students and how they evaluate the learning achieved. The third lens is the view of colleagues who can act as mirrors, mentors or constructive critics. Finally, the fourth lens in the Brookfield's model is the lens of literature, reading outside of one's area of practice can assist in locating and applying alternative theories of techniques to enrich practice. The Brookfield model has been chosen to promote critical reflection outside of one's normal

\footnotetext{
${ }^{6}$ J Mezirow (n.2)

${ }^{7}$ Brookfield (n.3)
} 
Katherine Langley

Leeds Beckett University

E: k.langley@leedsbeckett.ac.uk

Tw: @KatlLangley

parameters; Ndebele ${ }^{8}$ offers the metaphor of people conducting analysis being trapped in a prison of their own perceptual frameworks. In breaking away from ones usual perceptions, we can be more effective in critical reflection.

Watson and Kenny ${ }^{9}$ confirm that there is no singular, easy answer to help develop critical reflection in others. Aronson ${ }^{10}$ offers twelve tips on teaching critical reflection, as summarised below:

1. Define reflection

2. Decide on learning goals for the reflective exercise

3. Choose an appropriate instructional method for the reflection

4. Decide on using a structured or unstructured approach and create a prompt

5. Make a plan for dealing with ethical and emotional concerns

6. Create a mechanism to follow up on learners plan

7. Create a conducive learning environment

8. Teach learners about reflections before asking them to do it

9. Provide feedback and follow up

10. Assess the reflection

11. Make reflection part of the larger curriculum to encourage it

\footnotetext{
${ }^{8}$ C Ndebele, "Using Evaluation as Action Research: Reflections on Teaching Practice Using Brookfield's Four Lenses Model." Anthropologist (2014) 17 2, p533-p541

${ }^{9}$ G P Watson and N Kenny, “Teaching critical reflection to graduate students", Learning to Live, Learning for Life, (2014) vol 7.

${ }^{10}$ L Aronson, "Twelve tips for teaching reflection at all levels of medical education." Medical Teacher, (2011) vol. 33(3), pp 200-205.
} 
Katherine Langley

Leeds Beckett University

E: k.langley@leedsbeckett.ac.uk

Tw: @KatlLangley

12. Reflect on the process of teaching reflection.

The data that follows charts our own process of reflection.

Reflection is a subject that draws many rolled eyes from students, and is linked with the metaphor of "picture a beach....imagine the sound of the waves..." Rogers ${ }^{11}$ lists confounding assumptions students may hold as we, as educators, ask for "reflection": Is it self-reflection? Reflection? Contemplation? Introspection? In a clinical legal setting reflection is viewed as a process where students actively participate and engage in an first-hand and genuine case (case study) with an intention to use the understanding gained by this experience to facilitate better actions or choices in future employment, as well as developing that student's overall effectiveness. In order to combat the reticence of some students to engage in personal reflection it should ideally be rolled out across Levels, and repeated across different modules with prompts given, and discussions had to follow up the reflection. An in-depth approach to reflection throughout the course would allow students to identify the reasons behind reflection, and engage with how to do it, developing these key skills concurrently with core legal knowledge.

Many law clinics employ reflective journal or interactive journals as a method of encouraging students to adopt a deeper reflection of their skills. Interactive journals would also help to scaffold reflection into the clinical legal setting, particularly now with the emergence of Twitter, discussion boards, WhatsApp, and other social media applications. It would be possible for educators to offer prompts to students to promote their reflection, and in turn

\footnotetext{
${ }^{11}$ R R Rogers, "Reflection in Higher Education: A concept analysis." Innovative Higher Education, (2001) vol 26(1) pp 37-57.
} 
Katherine Langley

Leeds Beckett University

E: k.langley@leedsbeckett.ac.uk

Tw: @KatlLangley

students should become more proficient in asking their own reflective questions. Whilst it could be viewed that prompting students in this way may stifle their reflections, and make their responses more prescriptive, Walde, Davis Reid, Monroe and Borkan ${ }^{12}$ comment that "by providing a dilemma, students can focus on the act of reflecting critically, rather than being pre-occupied with looking for their own challenge to reflect on.” The use of creative resources as in the pilot study below, aims to relax students into the process of reflection, and encourage self-evaluation. Epp ${ }^{13}$ identifies journaling as a form of reflection-on action and an effective teaching strategy. Keeping a reflective journal is not a new suggestion, with $\operatorname{Schon}^{14}$, suggesting that this method could help to address the gap between theory and practice, and also writing about experiences can help students in improving critical thinking skills.

\section{Colleague Evaluation}

Brookfield ${ }^{15}$ suggests that colleagues act as critical mirrors, reflecting back images of our own actions that often take us by surprise. Feedback received from colleagues regarding this resource was indeed unexpected, despite the overview of the resource being brief, it was noted without further explanation that it would nurture internal reflection within the students, and moreover, that this may be contrary to their existing values and morals leading to

\footnotetext{
${ }^{12}$ H S Wald, S W Davis, S P Reid, A D Monroe, and J M Borkan, "Reflecting on reflections: Enhancement of medical education curriculum with structured field notes and guided feedback." Academic Medicine, (2009) vol. 84(7), pp 830-837.

${ }^{13} \mathrm{~S}$ Epp, "The value of reflective journaling in undergraduate nursing education: a literature review." International Journal of Nursing Studies, (2008) vol 45(9) pp. 1379-1388

${ }^{14} \mathrm{D}$ Schon. The reflective practitioner, $\left(2^{\text {nd }}\right.$ Edition, Jossey-Bass, 2001)

${ }^{15}$ Brookfield (n.3)
} 
Katherine Langley

Leeds Beckett University

E: k.langley@leedsbeckett.ac.uk

Tw: @KatlLangley

Transformative Learning. Colleagues expanded upon initial evaluation of the pilot study resource stating that, "Students would be encouraged to think creatively, and actively distinguish the factual basis of the decision making and their own beliefs." By challenging these aspects of their own innate characters this could be suggested to be a true process of transformative learning. However, Malkki and Green ${ }^{16}$ comment that transformative learning whilst valuable, could be better enabled for students if the 'journey' was signposted, as in real terms a student being able to fully apply the transformation to their own values and beliefs is a process of years not academic weeks. This is perhaps a point for curriculum designers to try and anticipate the need to embed transformative learning through a course to recognise its real outcomes.

\section{$\underline{\text { Student Evaluation }}$}

The positive feedback and achieved learning of the students is supported by literature on critical reflection for personal development, Hatzipanagos and Lygo-Baker ${ }^{17}$ make reference to the importance of critical reflection for inexperienced lecturers in a University setting, suggesting that critical reflection works well in this group as the new lecturers are more receptive to feedback. The nature of the Law Clinic students' work is equivalent with that of a newly qualified legal practitioner, and accordingly, these students are similarly receptive to the

\footnotetext{
16 K Mälkki and L Green, "Navigational Aids: The Phenomenology of Transformative Learning", Journal of Transformative Education, (2014) vol. 12, no. 1, pp. 5-24.

17 S Hatzipanagos, and S Lygo-Baker, "Teaching observations: promoting development through critical reflection." Journal of Further and Higher Education, (2006) 30(4), pp. 421-431.
} 
Katherine Langley

Leeds Beckett University

E: k.langley@leedsbeckett.ac.uk

Tw: @KatlLangley

reflective purpose of the resource, not only aiding the students with their own reasoning skills, but perhaps, looking more inwardly at their own perceptions of a case, opinions, and practices.

Generally, all of the student feedback correlated, with all six students commenting it was an informative and stimulating or interesting session, the majority of the feedback was positive. Some students when asked what they did not enjoy commented on the length of the whole session, two hours, or the compulsory peer-to-peer work. The length of the session is set, and the students were given a break for respite, additionally, the students work in small groups of two and three within the Law Clinic, and should be more used to peer-to-peer work. These comments whilst valid are arguably more indicative of the personal preference of the learner, and not negative feedback specific to the resource.

With a changing market, and evolving economy, it is more important than ever for our law students to be adequately equipped for a very different job market. Susskind ${ }^{18}$ notes that, "There is growing evidence of the market for desirability of a legal profession that extend beyond conventional service to new fields such as legal risk management." Sawyer ${ }^{19}$ argues that creative teaching results in a greater understanding among learners, and is a type of learning that is more difficult to assess quantifiably. Sawyer's opinion highlights the distance that legal teaching has to travel in becoming more engaging, that is not to say that every lesson

\footnotetext{
${ }^{18}$ R Susskind, “Tomorrow's Laywers”, Defense Counsel Journal, (2014), pp 327-332.

${ }^{19}$ R K Sawyer "Creative Teaching: Collaborative Discussion as Disciplined Improvisation", Educational Researcher [H.W.Wilson - EDUC], (2004) vol. 33, no. 2, pp. 12.
} 
Katherine Langley

Leeds Beckett University

E: k.langley@leedsbeckett.ac.uk

Tw: @KatlLangley

in legal teaching lacks creativity, but rather the traditional methods of teaching in this subject are lecture and seminar with little variation.

The QAA Benchmark Statement for $\mathrm{Law}^{20}$ includes several elements which elude to critical thinking, and reflection, but without comment as to how these are to be achieved. The statements suggests the following as a law student's skills and qualities of mind. "2.4 ii: selfmanagement, including an ability to reflect on their own learning, make effective use of feedback, a willingness to acknowledge and correct errors and an ability to work collaboratively." Further, at 2.4.xii, "engagement with their own personal and professional development, and academic integrity." Within many LLB Course Specifications, these reflective and critical thinking skills are included in Career Development or Employability modules, and completed at Level 4.There is some merit in the argument that law students are taught these skills implicitly and repeatedly throughout the course of their studies, in that sense that in most core legal subjects students are required to solve legal problems $\left(\mathrm{James}^{21}\right) \mathrm{A}$ question posed by this repeated legal problem solving is whether or not this is true reflection, or just a question and answer exercise? How can we ensure that students are reflecting on their own progress in a way that improves engagement?

Legal reasoning is often taught in a formulaic approach with students taught to identify the issues, identify the relevant law, apply the law to the problem and draw a conclusion, these,

\footnotetext{
${ }^{20}$ QAA Subject Benchmark Statement: Law (2015) Available at http://www.qaa.ac.uk/en/Publications/Documents/SBS-Law-15.pdf (Accessed on 25.03.2017)

${ }^{21} \mathrm{~N}$ James, "Logical, Critical and Creative: Teaching 'thinking skills' to law students." QUT Law and Justice. (2012) 12(1) pp. 66-88.
} 
Katherine Langley

Leeds Beckett University

E: k.langley@leedsbeckett.ac.uk

Tw: @KatlLangley

and similar approaches are labelled with acronyms, in this case IRAC. Metzler ${ }^{22}$ comments that methods including IRAC are important mental exercises forcing students to use a deeper understanding of the legal issues at stake; he argues that using IRAC is the key to success in law school assessments, and a successful career in the law. Whilst for some students, this blinkered approach to one problem in one module will be easily adopted and followed, in practice, there is rarely a clear-cut or singular issue to be dealt with. This begs the question of how well we are preparing our students for an effective and diverse legal practice? Taylor ${ }^{23}$ opposes the IRAC approach, suggesting that a step-by-step approach emphasises form over content, and leads to a false picture of legal problem solving. The balance could be struck by starting off with a method of problem solving, and gradually removing the scaffold of the step by step techniques in favour of a greater emphasis on legal reasoning, and consideration of other external factors including commercial considerations, non-adversarial options, and legal risk management. This development of practical skills could be built quite naturally into the progress of a student between Level 4 and 6.

Healthcare educators have long established reflection in education as good practice, teaching their students to function in a complex and ever-changing environment. Fostering a culture of continuous professional development in order to allow appropriate identification of multifaceted clinical problems. Pretorius and Ford ${ }^{24}$ confirm that, "the goal of reflective

\footnotetext{
${ }^{22}$ J Metzler, "The importance of IRAC and Legal writing." University of Detroit Mercy Law Review, (2002) vol 501.

${ }^{23}$ G Taylor, "Structured Problem-Solving: Against the 'Step-By-Step' Method" Deakin Law Review (2006) 11(1) 89. 61

${ }^{24}$ L Pretorius and A Ford, "Reflection for Learning: Teaching reflective practice at the beginning of University study. ” International Journal of Teaching and Learning in Higher Education. (2016) Vol 28 (2) pp. 241-253.
} 
Katherine Langley

Leeds Beckett University

E: k.langley@leedsbeckett.ac.uk

Tw: @KatlLangley

practice is self-discovery; purposely revisiting events with the need to learn from these situations will better enable a person to prepare for, and successfully deal with, future events of a similar nature." The ability of a student to link knowledge and practice together results in a deeper learning, improves learning in a clinical setting, and promotes a more positive learning experience for students. Current undergraduate curriculum in law is relatively freestanding, with little or no practical application of student's knowledge to practice until the commencement of post-graduate legal studies. There are of course, now a number of exempting degrees with allow students to study law, and legal skills concurrently; it would be interesting to research the reflective practices of these types of courses, though they are not indicative of the method in which most law students are taught.

Clinical legal education goes towards the idea of "core plus more." Increasingly, producing people capable of generating the kind of representation expected today requires that the core of legal education is not to be limited to legal theory. Law students today need to set themselves apart, even more so than before, and recognise that in a world of constant economic, social and political change, and against scores of other equally legally trained people, and sources of legal advice, knowing the law will no longer be sufficient to set them apart. This recognition, however minor to begin with, is a start to reflective skills, and the first step in making students' skill multifaceted. If, as Law Schools, we can assist students in improving their reflective skills then we are also improving our own strategies for teaching and learning. Jukier ${ }^{25}$ suggests, "If students are introduced to legal concepts within reference to modular or doctrinal boundaries, they will be less inclined to apply mechanistically what seem to be formulaic responses to legal

\footnotetext{
${ }^{25}$ R Jukier, "Transcending boundaries in legal education: a vehicle for teaching students to think critically." Collected essays on learning and Teaching, (2013) vol 6, pp 23-27.
} 
Katherine Langley

Leeds Beckett University

E: k.langley@leedsbeckett.ac.uk

Tw: @KatlLangley

issues, and more open to thinking about legal problems holistically." This more practical approach arguably better prepares students for the rigours of employment in legal or other sectors.

Reflection within a clinical legal setting provides students with not only an authentic legal problem, and a real client, but also a genuine opportunity for reflection. Aronson ${ }^{26}$ writes, "Reflective exercises require the establishment of a positive learning climate through the use of an authentic context, and the creation of a safe and supportive environment for reflection. This paper demonstrates the importance of reflection in emerging clinical legal education, and supports its viability as a creative teaching strategy, and its importance to the preparations of law students for life as a lawyer.

The consideration of reflection fits well within a clinical legal education setting as students have access to a more professional, and practical legal experience, and as such, it could be suggested that they are more open to the notion of reflection. Students within this setting are also, usually, at the beginning of their practice career, and keen to start with good habits. Students at this stage of their studies (generally Level 5 and 6) have an idea about the types of things they would like to practice in future, and the steps to take to make this aspiration a reality.

${ }^{26}$ L Aronson (n.10) 
Katherine Langley

Leeds Beckett University

E: k.langley@leedsbeckett.ac.uk

Tw: @KatlLangley

Porntaweekul, Kaksasataya and Nethonomsak ${ }^{27}$ offer three methods to support student reflection, which could be incorporated more broadly into all levels of the curriculum: namely, reflective learning environments, reflective teaching methods, and reflective scaffolding tools. At Leeds Beckett University, students complete reflective logs at Level 4 within their Career Development Module, asking broad questions like, what has been the attribute you have developed the most across the module? What is your weakness, and what is your strategy for overcoming this? This type of broad reflection is a good start but need to be more entrenched and understood by the students as a process to be an effective teaching and learning resource. As suggested above, the use of social media, and Virtual Learning environments could assist students in supporting reflective learning environments, and reflective scaffolding tools. Herstein $^{28}$ offers advice to the next generation when considering how to be adaptive and responsive as lawyers, "first learn management skills... make yourself easy to manage as well as managing others. Learn to understand the concept of value, your own, and that of your skills", this advice essentially confirms that students should be reflective, a lesson we can all learn from.

\section{$\underline{\text { Reflection as educators }}$}

Clinical legal education is a form of voluntary apprenticeship on a small scale, but this should not mean that we as educators are allowing critical thinking, and reflection to also be on a small

\footnotetext{
${ }^{27}$ S Porntaweekul, S Raksasataya, and T Nethonomsak, "Developing reflective thinking instructions model for enhancing student' desirable learning outcomes." Educational Research and Reviews, (2016) vol. 11(6) pp.238251.

${ }^{28}$ C Herstein, “The changing legal market: some thoughts for law students. ” Of Counsel, (2016) pp 6-13
} 
Katherine Langley

Leeds Beckett University

E: k.langley@leedsbeckett.ac.uk

Tw: @KatlLangley

scale. The goal of this type of legal education is to ensure that students, who have some underpinning, and core knowledge, engage with an intellectual and diverse experience, developing their skills of reflection, insight, and enabling them to see past the somewhat entrenched structures of the legal system. Evidence suggests that incorporating visual aids, and exercises into learning environments can help students develop higher-level cognitive skills, such as "thinking like a lawyer." Burgess ${ }^{29}$ argues that the legal curriculum traditionally teaches to the lowest four levels of learning (Bloom's taxonomy ${ }^{30}$ ) and tests the highest four. By including reflection exercises within legal curricula, students would be required to engage in a multi-modal approach and in turn, increase their effectiveness in legal reasoning.

There are within other professions entrenched reflective practices, and this is not true of law or legal education. This unusually backwards practice could be argued to be attributed to the common ego-competition amongst lawyers, and the competitive nature of legal practice in general. As legal practitioners it is difficult ever accept that we could have done a better job, or that something in your practice failed! An indication of the traditional, archaic and perhaps typically British stiff upper-lip, which has been the foundations of our legal system, and in contrast to the more caring professions. This explanation though, does not extend to educators, and perhaps the answer here is that we need more training, and conversations of what reflection is to be able to then impart that knowledge to others. A report by the American Philosophical

\footnotetext{
${ }^{29} \mathrm{H}$ Burgess, "Deeping the discourse using the legal mind's eye: lessons from neuroscience and psychology that optimise law school learning.” Quinnipiac Law Review. (2011), Vol. 29 Issue 1, p1

${ }^{30}$ B S Bloom, M D Engelhart, W H Hill, E J Furst, and D R Krathwohl, Taxonomy of Educational Objectives: Cognitive Domain. (Longman, 1956).
} 
Katherine Langley

Leeds Beckett University

E: k.langley@leedsbeckett.ac.uk

Tw: @KatlLangley

Association, Critical Thinking; A statement of expert consensus for purposes of educational assessment and instruction ${ }^{31}$, commented on the critical thinking as an outcome of university legal education, "Critical thinking is essential as a tool of inquiry. As such, critical thinking is a liberating force in education and a powerful resource in one's personal and civic life." If as educators we can invest our time in to promoting this skill then arguable students will be better able to measure their own performance, engage with improving their grades, and leave higher education as more rounded and proficient individuals.

On reflection, it is remarkable how little students, principally in Higher Education, are encouraged to think problems through critically. Amsterdam ${ }^{32}$ avers that this is perhaps inescapable in legal teaching, as the students have to be brought up to speed technically, on a broad range of subjects, it is almost inferred that these higher-level students have already developed problem solving skills. One could further argue that the very nature of law is didactic, and accordingly, there is no actual method for true conversations to occur in legal teaching, but more often a strict communication between teacher and student. In this respect, the resource in the pilot study worked well to break down some of the more entrenched and archaic practices for legal teaching and invited creativity into the legal classroom. Fitzpatrick

\footnotetext{
${ }^{31}$ American Philosophical Association, (1990) Critical Thinking: A statement of expert consensus for purposes of educational assessment and instruction, California Academic Press.

32 A Amsterdam, "Teaching about justice through creative strategies." Cleveland State Law Review. (1992) 40(413). Pp413-423.
} 
Katherine Langley

Leeds Beckett University

E: k.langley@leedsbeckett.ac.uk

Tw: @KatlLangley

and McConnell ${ }^{33}$ consider that students must obtain higher levels of cognitive learning whilst engaging in critical thought to become successful in a more globalised manner. The resource specifically challenges students to think critically, and in doing so, opens up the higher levels of Bloom's Taxonomy Learning outcomes in the Synthesis and Evaluation levels of the taxonomy are highest because they contain aspects of all the other levels and personal value judgements based on clearly defined criteria, this argument is wholly applicable to the pilot study resource as it concerns critical thinking, personal values and evaluation.

There is enormous scope for the pilot study resource to be developed further depending on the length of lesson, level of learners and topic covered. The method of skydiving analysis fits together with any type of critical analysis, weighing positives and negatives, more general evaluation and critical thinking, and as Hillier ${ }^{34}$ suggests this method bridges the gap between theory and practice. As an example, the resource could be utilised for character construction in English or Drama and has a multi-faceted application in practical legal teaching, judicial decisions, and case analysis, considering aggravating and mitigating factors, and weighing evidence.

\section{Conclusions}

Interactive reflection is a strong creative resource for any subject requiring critical thinking. In law, this has proved a most useful exercise, however, it emphasises that whilst there is great value in critical reflection, sometimes, there is a greater need to remain objective, where ethical

\footnotetext{
${ }^{33}$ L E Fitzpatrick, and C McConnell, "Intentionally evaluating course and project design for achieving global contextual learning", Journal of Instructional Pedagogies, (2012) vol. 7, pp. 1.

${ }^{34} \mathrm{Y}$ Hillier, Reflective Teaching in Further and Adult Education. ( ${ }^{\text {rd }}$ Edition, Continuum, 2011)
} 
Katherine Langley

Leeds Beckett University

E: k.langley@leedsbeckett.ac.uk

Tw: @KatlLangley

and legal obligations arise. In measuring the success of the pilot study resource, it may be prudent to revisit Aronson's twelve tips for teaching critical reflection. ${ }^{35}$ The pilot study resource is designed in essence to be a hidden reflection; students should work through the exercise organically, and upon completion be able to recognise that they have consolidated skills in reflection and critical thinking. The resource uses the structured approach and prompts, and assessment of the reflection as referenced by Aronson: however, the incorporation of more of the twelve tips could lead to wider applicability across legal curricula. Returning to thoughts of Jeffrey and $\mathrm{Craft}^{36}$ even in more academic disciplines, such as law, there is no bar to creativity in pedagogic practice if the focus becomes equally the teacher and the learner and the personal and professional development of both in the reasoning skydive. James ${ }^{37}$ asserts it is possible that development of legal teaching should lead to all students completing a separate module on logical and critical thinking. This perhaps opens the floodgates somewhat, and arguably, this is a discussion for curriculum designers, and module leaders as this has an implication for wider stakeholders. As alluded to by Malkki, and Green, ${ }^{38}$ above, the process of transformative learning is subject to a great deal of further ongoing research, and only when students begin to apply the process to other aspects of their learning, familiarising themselves with it, will they be able to reap the benefits and become more aware of their own position within their professional roles.

\footnotetext{
${ }^{35}$ L Aronson (n.10)

36 B Jeffrey, and A Craft, "Teaching creatively and teaching for creativity: distinctions and relationships."

Educational Studies, (2004) 30(1), pp. 77-87

${ }^{37} \mathrm{~N}$ James (n.20)

${ }^{38}$ K Mälkki and L Green (n.16)
} 
Katherine Langley

Leeds Beckett University

E: k.langley@leedsbeckett.ac.uk

Tw: @KatlLangley 